\title{
Recreación de la obra de arte como fuente de aprendizaje e invención creativa
}

Noemí Sánchez-Carralero Carabias noesanchezca@gmail.com

Facultad de Ciencias Humanas y Sociales de la Universidad Pontificia de Salamanca, España Rafael Sánchez-Carralero Carabias rasancaz@pin.upv.es

Facultad de Bellas Artes de la Universidad Politécnica de Valencia, España

Reference

Carabias, Noemí Sánchez-Carralero; Carabias, Rafael Sánchez-Carralero; (2012) "Recreación de la obra de arte como fuente de aprendizaje e invención creativa", p. 327-336. In: Barbosa, Helena; Quental, Joana [Eds]. Proceedings of the 2nd International Conference of Art, Illustration and Visual Culture in Infant and Primary Education. São Paulo: Blucher, 2015. ISSN 2318-695X, ISBN: 978-989-98185-0-7

DOI 10.5151/edupro-aivcipe-62

Resumen

El arte forma y ha formado parte integral de la vida del ser humano desde siempre. Le ha servido como medio de expresión y comunicación, y ha fomentado la evolución de su capacidad creativa. Es fundamental, por tanto, potenciar desde los primeros estadios formativos no solo la creación artística, sino también la capacidad de observar y comprender las obras de arte, desarrollando la sensibilidad artística. En este artículo presentamos el proceso, los resultados y las conclusiones obtenidas en la experiencia docente "Recreación de la obra de arte como fuente de aprendizaje e invención creativa" Ilevada a cabo con estudiantes de Magisterio. A través de técnicas diversas como el collage, el fotomontaje, la plastilina, las ceras, la estampación o el uso del ordenador, el estudiante aborda la interpretación de una obra artística reconocida. El principal objetivo es desarrollar la sensibilidad artística fusionando dos ejes fundamentales: la creación artística y la apreciación de las obras de arte.

Palabras clave Recreación, arte, educar

Abstract

Abstract. Art has always been an integral part of human life. It has served as a means of expressing and communicating, and has fostered the evolution of the creative abilities. It is therefore essential to encourage, from the early formative stages, not just artistic creation but also the ability to observe and understand the works of art by developing artistic sensibility. In this paper, we present the process, results and conclusions obtained in this educational experience conducted with teacher-training students. Through various techniques such as collage, photomontage, plasticine, crayons, stamping or computer, the student addresses the interpretation of a well known work of art. The main objective is to develop the artistic sensibility by combining two key areas: artistic creation and appreciation of art.

Keywords

Re-creation, art, education

\section{Introducción}

\begin{abstract}
... todos los espacios pueden percibirse como museos, los hogares con sus alfombras, muebles, cortinas; la gastronomía con sus colores, texturas, formas, olores y sabores; las calles con su mobiliario urbano, sus jardines, sus escaparates. Sin embargo, solo podrá gozar de estos magníficos juegos de espejos artísticos quien haya sido formado para apreciarlos. La sensibilidad artística, la capacidad de contemplación creativa, la cultura comparativa de épocas, estilos, soportes, artes y la posibilidad de una percepción conmovedora forman parte de lo que nuestro alumnado (niño, joven, adulto, nativo o extranjero, con diferentes capacidades o circunstancias sociales) tienen que adquirir y desarrollar en los centros educativos a lo largo de la vida. (Reyzabal, 2005)
\end{abstract}

Es fundamental potenciar desde los primeros estadios formativos la creación artística y la capacidad de observar y comprender las obras de arte, desarrollando la sensibilidad artística. 
2nd International Conference Art, Illustration and Visual Culture in Infant and Primary Education $2^{\circ}$ Congreso Internacional

Arte, Ilustración y Cultura Visual en Educación Infantil y Primaria de Arte, llustração e Cultura Visual

na Educação Infantil e Primária

Por ello, inculcar la apreciación del arte desde la escuela es un importante punto de partida para la iniciación en el desarrollo de la capacidad de apreciar cualidades específicas, como los colores, las formas, las texturas y el modo en que se organizan, y llegar a establecer registros conceptuales y sensitivos para apreciar también otros ámbitos del mundo circundante.

El profesorado tiene la responsabilidad de potenciar el desarrollo de las competencias pertinentes en cada uno de los ámbitos de la formación. Teniendo en cuenta el marco curricular de la LOE, una de las competencias a desarrollar en la educación escolar obligatoria es la Competencia cultural y artística cuya adquisición supone conocer, comprender y valorar críticamente las distintas manifestaciones culturales y artísticas. A su vez supone conocer las principales técnicas y recursos de los diferentes lenguajes artísticos y utilizar los códigos artísticos para la propia expresión desarrollando la iniciativa, la imaginación y la creatividad (Giráldez, 2007). Por ello creemos que es fundamental que desde el ámbito de la formación del profesorado se potencie en los futuros maestros la apreciación del arte, con el fin de que estos posteriormente desarrollen en los niños y niñas con mayor éxito la capacidad para respetar, valorar y disfrutar de las obras de arte mediante la percepción, el análisis y la interpretación de las mismas.

Con la experiencia que se recoge en el presente trabajo se expone una propuesta didáctica realizada con estudiantes de Magisterio que en el futuro desempeñarán su labor docente en las etapas de educación infantil y primaria. Una de las finalidades que tiene la educación plástica es "apreciar y analizar obras plásticas e imágenes y ofrecer herramientas para crearlas" (Caja, 2003:15) Con este propósito se forma a los jóvenes maestros en la aproximación al conocimiento de ciertas obras artísticas y a los procedimientos empleados en la elaboración de las mismas. A su vez desarrollan su capacidad creadora a través de trabajos prácticos de transformación de una obra o de la combinación creativa de varias obras de arte ya creadas. La finalidad última es que los futuros maestros puedan llevar a cabo su labor como guías del aprendizaje de sus alumnos en la escuela, fomentando la intervención activa de los mismos y generando nuevas experiencias creativas.

\section{Una experiencia a través de la recreación de obras de arte}

Generalmente el niño no tiene la iniciativa de aprender o estudiar obras de arte, ni se preocupa de cómo los elementos que aparecen en ellas están organizados para transmitir diversas sensaciones o intenciones. Para desarrollar su capacidad apreciativa es necesario que el guía de su aprendizaje fomente el desarrollo de la observación y genere con este objeto diversas experiencias en el aula. Se trata de que el niño desarrolle capacidades de apreciación de las obras de arte. El sentido de búsqueda constante, el ser testigo de la naturaleza cambiante, son fuentes de inspiración para la transformación y recreación de obras de arte. Como se ha comentado, a un niño no se le ocurre estudiar obras de arte, y trabajar a partir de ellas, transformándolas, recreándolas. No se le ocurre explorarlas para comprender cómo se utilizan los colores, las texturas o cómo se expresa por ejemplo el concepto de movimiento en las obras. Tampoco pretende, por iniciativa propia, crear variaciones sobre sus trabajos en busca de composiciones diversas a partir del uso premeditado de los elementos del lenguaje visual. Pero su capacidad de aprender hace posible que con propuestas y motivaciones adecuadas, el niño investigue, desarrolle su capacidad de observación y análisis, recurra a sus experiencias sensoriales, afectivas, cognitivas, e imagine y cree según sus particularidades individuales. Una de las labores del maestro en este campo es valorar la importancia del arte como forma de representación de las experiencias, por ello es importante por un lado potenciar el enriquecimiento de las mismas, y por otro potenciar el conocimiento de los medios específicos de representación. Mariana Spravkin, como se desprende directamente de sus propias palabras, valora manifiestamente la significación de la aportación cultural de la escuela y del docente para el desarrollo de la capacidad de indagación en la formación del alumno.

El interés de los chicos no es algo dado por su condición de tales sino una construcción cultural que seguramente se apoya en inclinaciones personales, pero que además se sustenta en la variedad y la calidad de experiencias por las que se ha transitado.

La curiosidad de los niños se construye en interacción con el medio, del cual la escuela como ámbito y el docente como nexo forman parte. 
2nd International Conference Art, Illustration and Visual Culture in Infant and Primary Education $2^{\circ}$ Congreso Internaciona

Arte, Ilustración y Cultura Visual en Educación Infantil y Primaria
${ }^{\circ}$ Congresso Internacional

de Arte, Ilustração e Cultura Visual

na Educação Infantil e Primária

Atender a los intereses de los chicos desde el medio escolar significa comprometerse a la ampliación de su campo de referencias, en la convicción de que nuevos saberes y experiencias despertarán, a su vez, nuevos intereses (Spravkin, 1998:108)

Por otro lado, el texto de Barbosa expuesto a continuación clarifica la importancia del acercamiento a la lectura de la obra de arte como experiencia enriquecedora en la formación integral del alumno.

\begin{abstract}
Al leer, estamos entrelazando informaciones del objeto, sus características formales, cromáticas, topológicas; informaciones del lector, su conocimiento acerca del objeto, sus interferencias y su imaginación. Así la lectura depende de lo que está enfrente y detrás de nuestros ojos. De esta forma, se produce una construcción de conocimientos visuales. La mirada de cada individuo está impregnada de experiencias pasadas, asociaciones, recuerdos, fantasías, interpretaciones, etc. (...) la lectura de una obra consiste en saborearla en sus diversos aspectos creando distintas interpretaciones. De igual modo podemos decir que, la lectura de una obra de arte es una aventura en la cual la cognición y sensibilidad se entrelazan en la búsqueda de significados (Barbosa, 2004:39-40)
\end{abstract}

Iniciar al niño en la lectura de la obra de arte le introduce en el proceso de comprensión del lenguaje visual y de la valoración estética, además de ser un apoyo significativo para la elaboración de sus actividades plásticas. Por ello, una vez trabajada la apreciación de la obra artística es de sumo interés abordar la reinterpretación de la misma lo que permite que el niño reconstruya un nuevo contexto con un nuevo sentido y significado.

En la escuela infantil existe un interés por el arte contemporáneo debido a que sus formas de expresión son más cercanas en el tiempo. La cultura de las imágenes a través de los medios de comunicación también está presente en las experiencias de los niños. En las escuelas además se trabaja con técnicas y procedimientos propios de las vanguardias artísticas como son el collage, el frottage, utilización de material de reciclaje, unión de pintura y escultura, abstracción geométrica o informal, potenciación exclusiva del color o de la textura, fotomontaje, uso de fotocopias... (Bartoloméis, 2001)

En la propuesta llevada a cabo con estudiantes de la titulación de Magisterio, de la que exponemos a continuación algunos ejemplos, se procede a la relectura de la obra de arte a través de una serie de técnicas específicas, tomando como referente creaciones significativas de autores destacados, entre ellos Van Gogh, Sorolla, Munch, Picasso, Derain, Vlaminck, Matisse, Klimt, Kandinsky, Klee, Hundertwasser... Se busca que el alumno interprete las obras artísticas escogidas con otros materiales procedimentales diferentes a los utilizados en las obras originales, potenciándose el desarrollo de su capacidad creativa. Dependiendo de la técnica que utilice para su labor recreadora se fomenta un aprendizaje centrado en el esfuerzo por conseguir una paleta rica en matices de color (ceras, plastilinas, témperas), se persigue traducir creativamente una pintura al lenguaje del papel (recortado, rasgado, arrugado, troceado) integrando en ocasiones materiales variados como lanas, tejidos, plásticos... o interrelacionar creativamente diversas obras a través del ordenador.

Figura 1 y 2. A la izquierda: Recreación de la obra "Le Restaurant de la Machine à Bougival" de Vlaminck. Ceras. Alumna I.Giner (2010) Fuente: propia. A la derecha: Recreación de la obra "La Seine à Chatou" de Vlaminck. Plastilina sobre papel. Alumna L. Fontán (2010) Fuente: propia.
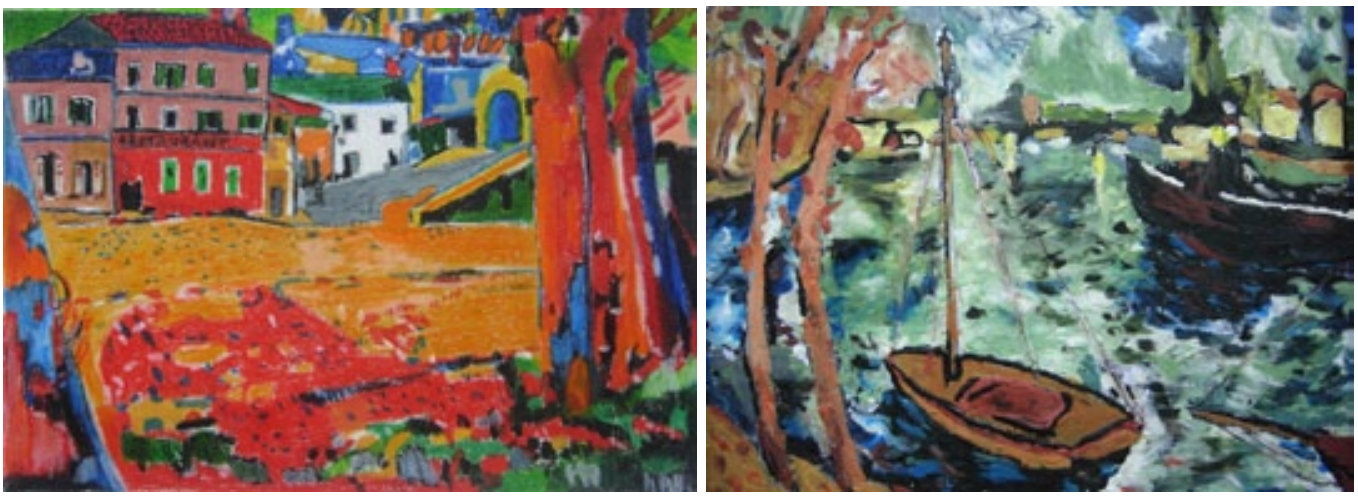

Las ceras blandas (fig.1), al ser un material muy moldeable, pudieron utilizarse de formas variadas: frotándolas sobre el papel, superponiendo los colores para aumentar la cantidad de matices, extendiéndolas con el dedo creando superficies de matiz algodonoso, creando 
nternationa conference

Art, Illustration and Visual Culture in Infant and Primary Education
${ }^{\circ}$ Congreso Internaciona

Arte, Ilustración y Cultura Visual en Educación Infantil y Primaria de Arte, llustração e Cultura Visual

na Educação Infantil e Primária
Figura 3 y 4. A la derecha: Recreación de la obra "Doce girasoles en un jarrón" de Van Gogh. Collage. Alumna N.Franco (2010). Fuente: propia. A la derecha: Recreación de la obra "El beso" de Gustav Klimt. Técnica de estampación con témperas. Alumna R.Sánchez (2010). Fuente: propia. esgrafiados al rayar sobre las diferentes capas superpuestas... Con esta técnica se pretendió realizar un acercamiento a los procesos pictóricos empleados en las obras seleccionadas. La plastilina (fig.2) fue utilizada creando bajorrelieves extendiéndola con el dedo sobre el papel. Se priorizaba la mezcla de colores creando una paleta variada de matices. Como a cualquier masa moldeable se le podían hacer estampaciones, huellas, marcas, incisiones que en ocasiones complementaban el trabajo.
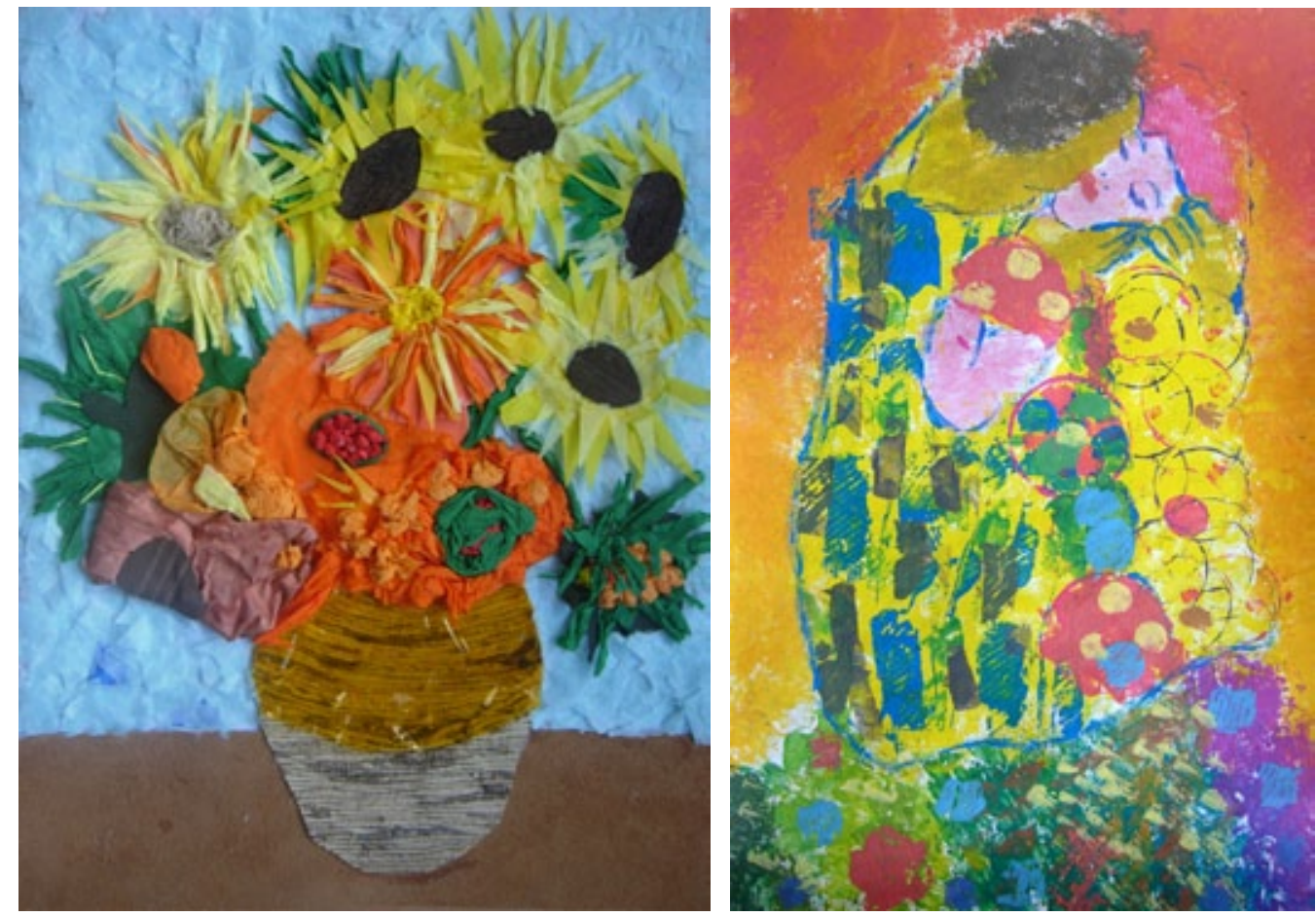

Con el collage (fig.3) se abordó la recreación a partir del recorte de formas de distintos materiales, colores y texturas para organizar sobre el soporte una composición. Permitió desarrollar capacidades perceptivas, manipulativas, compositivas e imaginativas y poder organizar los elementos de diferentes modos antes de decidirse por una solución y proceder al fijado de los materiales. Con las témperas (fig.4) se aplicó la técnica de estampación a partir de sellos creados con diferentes tipos de materiales: corchos, patatas, zanahorias, cartón... También se procedió al estampado de cuerdas, hilos, redecillas, esponjas, dedos... empapadas en pintura. Con el ordenador y la utilización de programas básicos de manipulación de la imagen (fig.5) se crearon fotomontajes en los que el alumno podía combinar creativamente fragmentos de obras ya creadas transformando y reconstruyendo un nuevo contexto con nuevos significados.

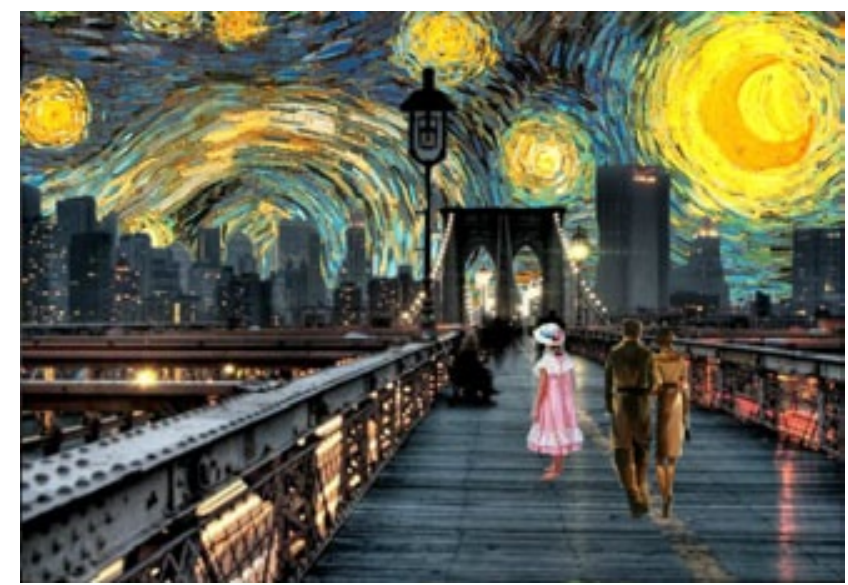




\section{Conclusión}

\section{Referencias bibliográficas}

Arnheim, R. (1974). Arte y percepción visual. Madrid: Alianza Forma (2002)

Barbosa, B. (2004). La estampa en la enseñanza primaria. Metodología para la Educación Plástica. Málaga: Aljibe.

Bartoloméis, F. (1994). El color de los pensamientos y los sentimientos. Barcelona: Octaedro.

Caja, J. et al. (2003). La educación visual y plástica hoy. Educar la mirada, la mano y el pensamiento. Barcelona: Graó.

Giráldez, A. (2007). Competencia cultural y artística. Madrid: Alianza.

Reyzabal Rodríguez, M.V. en Fernández-Oliva, S. (2005). La creatividad de la mirada. Conserjería de Educación de la Comunidad de Madrid.

Spravkin, M. (1998). Enseñar plástica en la escuela: conceptos, supuestos y cuestiones. En AA.VV. Artes y Escuela. Buenos Aires: Paidós Cuestiones de educación. 